\title{
Lack of concern deepens the oceans' problems
}

\author{
Research has exposed flaws in marine conservation, yet little is written and less is cited.
}

Sir - There is a crisis in the world's oceans ${ }^{1-4}$. Myriad human impacts - from coastal development, pollution and habitat alteration to introduction of invasive species, overfishing and climate change - seriously jeopardize marine ecosystems and the services they provide. How much research is being done in these crucial areas?

Earlier analyses in the period up to 1996 documented that marine ecosystems were represented by only around $5 \%$ of papers in two main applied-ecology journals ${ }^{5,6}$. We have discovered that there is still, eight years later, negligible emphasis on marine issues in the conservation-biology literature and that conservation receives very limited attention in the general marine and fisheries literature. For example, only about $5 \%$ of papers in leading marine-ecological journals deal with pollution, nonindigenous species, overfishing or marine protected areas.

We next asked if the impact of terrestrial papers published in Conservation Biology differed from the impact of marine papers. To do this, we looked up every research paper published in Conservation Biology in 1997 in ISI's Web of Science and tallied the number of citations each paper received (we chose 1997 to allow time for papers to be assimilated into the literature). Papers on marine topics were cited an average of 7.1 (s.d. 3.5) times, whereas terrestrial articles were cited an average 18.2 times (s.d. 14.6). Thus, not only were fewer articles being published about marine conservation, but those that were published appeared to have less impact than research on terrestrial habitats.

Most attention to conservation issues has focused on the terrestrial realm, but it is clear that the oceans face an increasingly severe array of problems. Humans might well focus first on the habitat they themselves inhabit, but it is clearly time for more attention and resources to be directed towards the oceans. The limited rigorous scientific research that has been done has exposed many of the flaws in

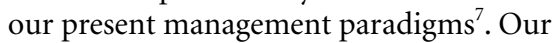
ability to overcome the problems will surely depend on the contributions of science.

\section{Beth F. Kochin, Phillip S. Levin}

Northwest Fisheries Science Center,

National Marine Fisheries Service,

Seattle, Washington 98112, USA

Literature and citation analyses available direct

from P.S.L.at phil.levin@noaa.gov

1. Myers, R. A. \& Worm, B. Nature 423, 280-283 (2003).

2. Baum, J. K. et al. Science 299, 389-392 (2003).

3. Jackson, J. B. C. et al. Science 293, 629-638 (2001).

4. Pew Oceans Commission. America's Living Oceans: Charting a course for sea change (Pew Oceans Commission, Arlington, Virginia, 2003).

5. Irish, K. E. \& Norse, E. A. Conserv. Biol. 10, 680 (1996).

6. Ormerod, S. J. J. Appl. Ecol. 40, 204-213 (2003).

7. Peterson, C. H. \& Estes, J. A. in Marine Community Ecology (eds Bertness, M. D. et al.) 469-509 (Sinauer Associates, Sunderland, Massachusetts, 2001).

\section{Impact factors: just part of a research treadmill}

Sir - In Brazil, scientists need to publish more every year to obtain scarce funds, leading to an exaggerated degree of competitiveness and promoting a cultural distortion where scientometrics prevails over knowledge (as discussed by P. A. Lawrence, Nature 422, 259-261; 2003 and in subsequent Correspondence). In this highly competitive atmosphere, Brazilian science is improving. But what is the impact on the individual, particularly on new PhDs who need to establish a career?

In 2001, the Ministry of Science and Technology created a programme to affiliate 10 promising young $\mathrm{PhDs}$ with research centres. There were 1,154 candidates for these 10 positions. In the same year, the National Research Council offered two-year research grants varying from US $\$ 2,000$ to $\$ 43,600$. For the section that included biochemistry, biophysics, physiology, pharmacology and neuroscience there were 437 applications, of which 267 were approved on merit but only 20 were funded. The main selection criterion for both programmes was based primarily on number of publications and impact of the journals concerned.

We interviewed postgraduate students, postdoctoral fellows and teaching staff in one department about their concerns. A common feature was a high degree of involvement with their work. A typical statement by a postgraduate student referring to the faculty was: "They must be crazy. They live, they eat, they will probably die in that laboratory. They arrive at $8 \mathrm{am}$ and never leave before 10pm. Why do you think they marry among themselves?". (The 39 established investigators included 13 married couples.)

On publication pressures, typical statements were: “[The adviser] doesn't care about my thesis as such. He believes that a thesis is the consequence of good work and good work means papers published in good journals." Referring to colleagues' work, people mention the number of publications and the journal, not knowing exactly what had been discovered. "They evaluate people by the number of publications ... and classify them by the impact of the journals: highimpact and low-impact scientists." Or: "If you publish a paper in Nature, marvellous, but if you do it in a Brazilian journal they will say, 'Look what a lousy contribution to science.." Submitting a paper evokes strong emotions: "When the journal does not accept ... you feel as if it is not only your paper but you yourself that is rejected". Or: "It is a great feeling to have a paper accepted ... when you know that so many people have their papers rejected.”

The difficulty of obtaining research support, in a country where funding is mainly public, generates strong feelings of insecurity at all levels. "You never know if you will have money, if your application is going to be approved." Or: "If you stop publishing you lose your grant ... You are ejected from the system; it doesn't matter what you did in the past - it only matters what you have done in the last two to three years." One respondent said: "I knew that they would post the result of the evaluation. ... I went to the computer. My heart was pounding inside me ... My name was there, I was awarded ... I started crying and I couldn't stop. ... I went and hugged my wife, crying ... and all of that for a lousy grant of less than US $\$ 8,000$ per year."

In universities where there is no research, the thesis defence is a rite of passage, legitimization as part of the teaching staff coming mainly from the academic title of $\mathrm{PhD}$. For a research postdoc, the analogy is the publication of a paper, but this affords only temporary respite, not a transition to a 'new world'. The doctoral thesis in itself is unimportant; what counts are 'papers published in good journals'. According to our interviews, legitimization never really arrives. The trajectory of the scientist becomes an increasingly difficult struggle for grants, where the individual may lose support at any time. The idea of a continuous, stable career is blurred. Instead people are in perpetual transition, repeatedly having to prove their capability, and at increased risk each year of either being eliminated or burning out if they remain in the system. Leopoldo de Meis ${ }^{\star}$, Maria Scarlet do Carmo ${ }^{\star}$, Carla de Meis $\dagger$

*Departamento de Bioquímica Médica, Centro de Ciências da Saúde, Universidade Federal do Rio de Janeiro, Rio de Janeiro 21941-590, Brasil $\dagger$ Instituto de Psiquiatria, Universidade Federal do Rio de Janeiro, Rio de Janeiro, 21941 590, Brasil 